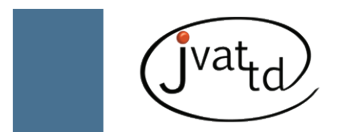

\title{
Candida spp.: manual identification (reference method) and automated identification (Vitek system platform)
}

Mondelli AL (1), Niéro-Melo L (1), Bagagli E (2), Camargo CH (2), Bruder-Nascimento A (2), Sugizaki MF (2), Carneiro MV (1), Villas Boas PJF (1)

(1) Department of Internal Medicine, Botucatu Medical School, São Paulo State University (UNESP - Univ Estadual Paulista), Botucatu, São Paulo State, Brazil; (2) Department of Microbiology and Immunology, Botucatu Biosciences Institute, São Paulo State University (UNESP - Univ Estadual Paulista), Botucatu, São Paulo State, Brazil.

\begin{abstract}
Yeasts are becoming a common cause of nosocomial fungal infections that affect immunocompromised patients. Such infections can evolve into sepsis, whose mortality rate is high. This study aimed to evaluate the viability of Candida species identification by the automated system VitekBiomerieux (Durham, USA). Ninety-eight medical charts referencing the Candida spp. samples available for the study were retrospectively analyzed. The system Vitek-Biomerieux with Candida identification card is recommended for laboratory routine use and presents $80.6 \%$ agreement with the reference method. By separate analysis of species, $13.5 \%$ of C. parapsilosis samples differed from the reference method, while the Vitek system wrongly identified them as C. tropicalis, C. lusitaneae or as Candida albicans. C. glabrata presented a discrepancy of only one sample (25\%), and was identified by Vitek as C. parapsilosis. C. guilliermondii also differed in only one sample (33.3\%), being identified as Candida spp. All C. albicans, C. tropicalis and C. Iusitaneae samples were identified correctly.
\end{abstract}

Key words: candidemia, Candida spp., identification, automated identification.

\section{INTRODUCTION}

A global increase in yeast incidence has been reported by several authors over the past 20 years. Among invasive infections caused by Candida spp., the blood infections known as candidemias are the most clinically relevant (1). Candida spp. is currently among the five main causes of blood infections in hospitals, and the increase in candidemia cases has been noted mainly among patients using antibiotics, under immunosuppressive therapy or parenteral nutrition and patients subjected to multiple invasive procedures $(2,3)$. Some studies estimate mortality atributed to Candida spp. to be $38 \%$, although it can vary from 50 to $60 \%$ (4-7). With regard to epidemiological aspects, identifying the yeast species is essential for monitoring hospital infection rates and for early identification of Candida infection outbreaks (8). Therefore quickly and accurately identifying the yeast species and treating the patient as soon as possible are all fundamental measures to increase survival.

The aim of this study was to comparatively evaluate different methods for identifying Candida spp.

We analyzed 98 yeast samples from different patients admitted to Botucatu Medical School's Clinical Hospital (HC-FMB) between the years of 2000 and 2006 and the charts of these patients (obtained at the Statistical Medical Service - SAME, property of HC-FMB). These patients developed candidemia symptoms and samples were isolated from hemocultures (Bactec ${ }^{\oplus}$ Aerobic, Peds or Myco/F, BD - Becton Dickinson, USA) by the Microbiology Sector of the Clinical Analysis Laboratory. Samples 
used in this study were stored in nutrient broth with cryopreservatives at $-70^{\circ} \mathrm{C}$, in the Cultures Collection at the Department of Microbiology and Immunology (at the Botucatu Biosciences Institute, UNESP).

Sample size was calculated using the formula of Fisher and Belle, with a 95\% confidence interval and $5 \%$ precision for expected prevalence of fungemia patients. We used as reference the study of Beck-Sagué and Jarvis (9), which had 10.4\% fungemia patients.

The growth medium used for yeast detection was Bactec hemoculture vials (Aerobic, Peds or $\mathrm{Myco} / \mathrm{F}, \mathrm{BD}$ - Becton Dickinson, USA); for isolation and identification were used Sabouraud dextrose agar 2\%, Columbia blood agar and Chromagar Candida (Difco, USA).

\section{Manual Identification Method}

Yeast species were identified according to morphological and biochemical characteristics. After isolation from hemoculture vials, tests were performed to verify germinative tube and chlamydoconidium production and filamentation, followed by tests of carbon and hydrogen assimilation and carbohydrates fermentation, as described below, following the methods prescribed by Kurtzman and Fell (10).

\section{Carbon and hydrogen assimilation}

A carbon auxanogram was used to evaluate the capacity to assimilate a different carbon source. Yeast suspension was incorporated into a synthetic base free of carbon and solidified. After that, 16 different carbohydrates were added to the plate, which was then incubated at $35^{\circ} \mathrm{C}$ for 24 and 48 hours. Any visible growth, indicated by turbidity on the spot of carbohydrate incorporation was defined as constituting positive assimilation.

\section{Fermentation of Carbohydrates (Zymogram)}

The capacity of yeasts to use certain carbohydrates as an energy source to produce ethanol and carbon dioxide $\left(\mathrm{CO}_{2}\right)$ was analyzed under low oxygen tension. $\mathrm{CO}_{2}$ production could be observed in a liquid growth medium with one carbohydrate and an inoculum with 6 carbohydrates in Durham tubes. Results were analyzed at 24, 48 and 72 hours and at 5, 10 and 14 days. This was considered the reference methodology.

\section{Automated Identification Method}

We used Vitek I (Durham, USA) as the automated identification method, which uses a plate with 40 different tests of carbohydrates and amino acids, incubated at $35^{\circ} \mathrm{C}$ for 24 to 48 hours. Data obtained were sorted into charts as well as frequency and association tables. Numeric variables were presented as mean and standard deviation, when variables presented symmetrical (normal) distribution, or median and percentiles, in case of asymmetrical distribution. Categorical variables were expressed by number and rate of events and evaluated by chi-square test or Fisher's exact test (if $\mathrm{n}<10$ ). Normal distribution variables were evaluated by Student's $t$ test and nonnormal variables by Wicoxon-Mann-Whitney test. ANOVA (analysis of variance) was used to compare three groups. Results were considered significant if $\mathrm{p}<0.05$. A concordance test was used to analyze laboratory assays.

This study was approved by Botucatu Medical School's Research Ethics Committee on October $2^{\text {nd }}, 2006$ (protocol number 2266/2006).

Using the reference method we identified in 98 samples: 37 Candida parapsilosis; 33 Candida albicans; 12 Candida spp.; 7 Candida tropicalis; 4 Candida glabrata; 3 Candida guilliermondii and 2 Candida lusitaneae.

Table 1 shows the concordance rate between the two identification methods evaluated (manual identification, considered the reference method, and automated identification, using the Vitek system) for Candida species identification. There was a global concordance of 79 samples (80.6\% of cases). Separate analysis of species found that five samples of $C$. parapsilosis differed from the reference method (13.5\%); Vitek wrongly identified one of these five samples as $C$. tropicalis, one as C. lusitaneae and three others as C. albicans. C. glabrata differed only in one sample (25\%), which was identified by Vitek as C. parapsilosis. One C. guilliermondii sample was wrongly identified by Vitek as Candida spp. (33.3\%). All samples identified as C. albicans, $C$. tropicalis or C. lusitaneae by the manual method were identified correctly by Vitek. Candida spp. samples differed in 12 samples (91.6\%), identified as C. albicans (six of them), C. parapsilosis (four of them) and C. tropicalis (one of them), and one was wrongly identified as Cryptococcus neoformans.

Even though candidemia can be diagnosed by isolation of Candida spp. from the blood 
Table 1. Comparison between manual and automated (Vitek I) identification

\begin{tabular}{|c|c|c|c|c|c|c|c|c|c|}
\hline \multirow[b]{2}{*}{$\begin{array}{c}\text { Manual } \\
\text { identification }\end{array}$} & \multicolumn{8}{|c|}{ Vitek } & \multirow[b]{2}{*}{ Tota } \\
\hline & $\begin{array}{l}\frac{n}{4} \\
\frac{0}{\bar{n}} \\
\frac{\sigma}{\sigma} \\
\vdots \\
\vdots \\
ن\end{array}$ & 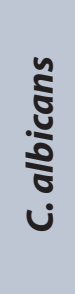 & $\begin{array}{l}\frac{0}{0} \\
\frac{0}{0} \\
\frac{0}{0} \\
ن\end{array}$ & ن & 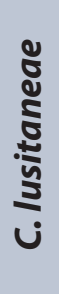 & 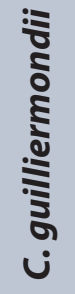 & $\begin{array}{l}\frac{0}{0} \\
\frac{0}{n} \\
\frac{0}{0} \\
\frac{0}{5} \\
5 \\
0\end{array}$ & 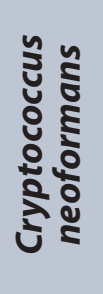 & \\
\hline C. parapsilosis & 32 & 3 & 0 & 1 & 1 & 0 & 0 & 0 & 37 \\
\hline C. albicans & 0 & 33 & 0 & 0 & 0 & 0 & 0 & 0 & 33 \\
\hline C. glabrata & 1 & 0 & 3 & 0 & 0 & 0 & 0 & 0 & 4 \\
\hline C. tropicalis & 0 & 0 & 0 & 7 & 0 & 0 & 0 & 0 & 7 \\
\hline C. Iusitaneae & 0 & 0 & 0 & 0 & 2 & 0 & 0 & 0 & 2 \\
\hline C. guilliermondii & 0 & 0 & 0 & 0 & 0 & 2 & 1 & 0 & 3 \\
\hline Candida spp. & 4 & 6 & 0 & 1 & 0 & 0 & 0 & 1 & 12 \\
\hline Total & 37 & 42 & 3 & 9 & 3 & 2 & 1 & 1 & 98 \\
\hline
\end{tabular}

of patients who present symptoms of blood infection, hemoculture is a low-sensitivity marker, with an elevated false-negative rate that hampers the diagnosis of this disease (11-14). This makes it difficult to decide when treatment should begin. On average, it takes from $2.1 \pm 1.3$ days to $5.1 \pm 3$ days to initiate treatment after obtaining a positive hemoculture, and many cases are only diagnosed during autopsy.

Candida spp. grows on regular growth media but positivity is very low even when the concentration is high. In premature patients the volume of blood used for hemocultures can be the cause of low sensitivity. There is a $65 \%$ chance of detecting bacteria when $1 \mathrm{~mL}$ of blood is used, but low concentrations and low replication rates can reduce growth rates in culture media, thereby increasing the time necessary to obtain positivity. Negative hemocultures do not exclude diagnosis, so serial samples must be analyzed (11-13).

Candida spp. identification and antifungal sensitivity tests are fundamental for therapeutical success. The choice of the Vitek I system platform as the automated method used for this study was based on the following reasons: a concordance rate above $80 \%$ when compared to the reference method; identification and antifungal sensitivity tests are performed in just a few hours, being useful for laboratories with great demand of said tests; it is able to identify Candida dubliniensis; this system presents low costs, when compared to other methods such as molecular biology techniques, and it also offers greater safety for operators and reduces repetitive manual operations $(15,16)$.

C. glabrata is not very sensitive to fluconazole, and Candida krusei is intrinsically resistant to fluconazole; therefore, they must be treated with amphotericin B or an echinocandin. C. lusitaniae is resistant to amphotericin $\mathrm{B}$, being treated with fluconazole. In this context, the choice of the correct antifungal drug is delayed until identification and sensitivity tests are performed. Yeast species identification is also important for monitoring rates of hospital infection, and for early identification of Candida infection outbreaks (8).

The use of different identification methods and sensitivity tests allows us to verify the quality of the results more accurately. When comparing the methods of identifying Candida spp., it becomes clear that the most effective tests are also the more time-consuming and laborious ones, which makes it very important that the laboratory routine have the ability to compare and correlate these methods, in order to choose 
the best one. This study analyzed two methods of Candida identification: one manual and more complex (morphological and biochemical tests), considered a reference method for many years before the introduction of molecular biology; and an automated method, using Vitek-Biomerieux (Durham, USA), which is faster and simpler.

When comparing these two distinct methods of Candida identification we can observe a global concordance of $80.6 \%$. The concordance rate for C. albicans $(\mathrm{n}=33)$, C. lusitaneae $(\mathrm{n}=2)$ and $C$. tropicalis $(\mathrm{n}=7)$ was $100 \%$. The concordance rates for other species were the following: $C$. parapsilosis - 86.49\%; C. glabrata - 75\% and C. guillermondii $-66.67 \%$. Even though the concordance rate for Candida spp. was $0 \%$, that can be explained by the fact that there is no such option on the Vitek system, what makes the system choose the most viable option, even if it is not necessarily the most accurate. These data allow us to conclude that the Vitek-Biomerieux semi-automated method can be used in the laboratory routine, although identification of certain species may require confirmation by another method.

Candida species peculiarities justify the need to identify yeast species when they are related to systemic diseases. This is essential for the choice of the best therapeutical approach for the patient. C. krusei isolates are totally resistant to fluconazole, while C. glabrata samples are often either resistant or not very sensitive to azoles, requiring a higher dose for treatment success. Higher doses of amphotericin B should also be used to treat invasive infections by C. krusei and C. glabrata, whereas C. lusitaniae isolates can be resistant to this drug $(17,18)$.

A fast and accurate technique for yeast identification is very important for microbiological laboratories. According to the results found in the present study, the automated system Vitek-Biomerieux (Durham, USA) with an identification card is recommended for use in routine laboratories.

\section{ACKNOWLEDGMENTS}

The authors are grateful for the support of FAMESP; the Clinical Hospital and Clinical Analysis Laboratory of Botucatu Medical School, and the Department of Microbiology and Immunology of the Botucatu Biosciences Institute, UNESP, Botucatu, SP.

\section{COPYRIGHT}

(C) CEVAP 2012

\section{SUBMISSION STATUS}

Received: March 28, 2012.

Accepted: June 15, 2012.

Abstract published online: June 29, 2012.

Full paper published online: August 31, 2012.

\section{CONFLICTS OF INTEREST}

The authors declare no conflicts of interest.

\section{FINANCIAL SOURCE}

The Medical and Hospital Development Foundation (FAMESP) provided the financial grants.

\section{ETHICS COMMITTEE APPROVAL}

The present study was approved by the Research Ethics Committee of the Botucatu Medical School, UNESP, under protocol number 2266/2006 CEP.

\section{CORRESPONDENCE TO}

Alessandro Lia Mondelli, Departamento de Medicina Interna, Faculdade de Medicina de Botucatu, UNESP, Distrito de Rubião Júnior, s/n, 18618-970, Botucatu, SP, Brazil. Phone: +55 14 3811 6213. Email: dralessandro@hotmail.com or alessandro@fmb.unesp.br.

\section{REFERENCES}

1. Colombo A, Guimarães T. Epidemiology of hematogenous infections due to Candida spp. Rev Soc Bras Med Trop. 2003;36(5):599-607.

2. Nucci M, Colombo A. Risk factors for breakthrough candidemia. Eur J Clin Microbiol Infect Dis. 2002;21(3):209-11.

3. França J, Ribeiro C, Queiroz-Telles F. Candidemia em um hospital terciário brasileiro: incidência, frequência das diferentes espécies, fatores de risco e suscetibilidade aos antifúngicos. Rev Soc Bras Med Trop. 2008;41(1):23-8.

4. Wey S, Mori M, Pfaller M, Woolson R, Wenzel R. Hospital-acquired candidemia. The attributable mortality and excess length of stay. Arch Intern Med. 1988;148(12):2642-5.

5. Karabinis A, Hill C, Leclercq B, Tancrède C, Baume $\mathrm{D}$, Andremont A. Risk factors for candidemia in cancer patients: a case-control study. J Clin Microbiol. 1988;26(3):429-32.

6. Bross J, Talbot G, Maislin G, Hurwitz S, Strom B. Risk factors for nosocomial candidemia: a casecontrol study in adults without leukemia. Am J Med. 1989;87(6):614-20. 
7. Komshian S, Uwaydah A, Sobel J, Crane L. Fungemia caused by Candida species and Torulopsis glabrata in the hospitalized patient: frequency, characteristics, and evaluation of factors influencing outcome. Rev Infect Dis.1989;11(3):379-90.

8. Ruiz L, Sugizaki M, Montelli A, Matsumoto F, Pires M, da Silva B, et al. Fungemia by yeasts in Brazil: occurrence and phenotypic study of strains isolated at the Public Hospital, Botucatu, São Paulo. J Mycol Med. 2005;15(1):13-21.

9. Beck-Sagué C, Jarvis W. Secular trends in the epidemiology of nosocomial fungal infections in the United States, 1980-1990. National Nosocomial Infections Surveillance System. J Infect Dis. 1993;167(5):1247-51.

10. Kurtzman CP, Fell JW. The yeasts: a taxonomic study. 4th ed. Amsterdam: Elsiever; 1998.

11. Weinstein M, Towns M, Quartey S, Mirrett S, Reimer L, Parmigiani G, et al. The clinical significance of positive blood cultures in the 1990s: a prospective comprehensive evaluation of the microbiology, epidemiology, and outcome of bacteremia and fungemia in adults. Clin Infect Dis. 1997;24(4):584602 .

12. Edwards JJ, Bodey G, Bowden R, Büchner T, de Pauw $\mathrm{B}$, Filler $\mathrm{S}$, et al. International conference for the development of a consensus on the management and prevention of severe candidal infections. Clin Infect Dis. 1997;25(1):43-59.
13. Ascioglu S, Rex J, de Pauw B, Bennett J, Bille J, Crokaert $\mathrm{F}$, et al. Defining opportunistic invasive fungal infections in immunocompromised patients with cancer and hematopoietic stem cell transplants: an international consensus. Clin Infect Dis. 2002;34(1):714.

14. Berenguer J, Buck M, Witebsky F, Stock F, Pizzo $\mathrm{P}$, Walsh T. Lysis-centrifugation blood cultures in the detection of tissue-proven invasive candidiasis. Disseminated versus single-organ infection. Diagn Microbiol Infect Dis. 1993;17(2):103-9.

15. Costa AR, Silva F, Henriques M, Azeredo J, Oliveira R, Faustino A. Candida clinical species identification: molecular and biochemical methods. Ann Microbiol. 2010;60(1):105-12

16. Cárdenes-Perera CD, Torres-Lana A, Alonso-Vargas R, Moragues-Tosantas MD, Pontón-San Emeterio J, Quindós-Andrés G, et al. Evaluation of API ID 32C and VITEK-2 to identify Candida dubliniensis. Diagn Microbiol Infect Dis. 2004;50(3):219-21.

17. Sanglard D, Odds F. Resistance of Candida species to antifungal agents: molecular mechanisms and clinical consequences. Lancet Infect Dis. 2002;2(2):73-85.

18. Pfaller M, Diekema D, Messer S, Boyken L, Hollis R. Activities of fluconazole and voriconazole against 1,586 recent clinical isolates of Candida species determined by Broth microdilution, disk diffusion, and Etest methods: report from the ARTEMIS Global Antifungal Susceptibility Program, 2001. J Clin Microbiol. 2003;41(4):1440-6. 